\title{
Review
}

\section{Effect of Coffee on Gastroesophageal Reflux Disease}

\author{
Yu ZHANG ${ }^{1}$ and Shao-hua CHEN ${ }^{2 *}$ \\ ${ }^{1}$ Internal Medicine, Zhejiang Hospital, No.12, Lingyin Road Hangzhou 310013, China \\ ${ }^{2}$ Department of Gastroenterology, The First Affiliated Hospital, College of Medicine, Zhejiang University, No.79, Qingchun Road Hangzhou, \\ 310003, China
}

Received July 28, 2012; Accepted September 1, 2012

Coffee is the most popular drink in the world and coffee intake may be a risk factor for gastroesophageal reflux disease (GERD), which is a common disorder and its worldwide prevalence is increasing. However, the effect of coffee on GERD remains to be fully elucidated. The relationship between GERD and coffee consumption is not clear given the existing literature, whose results are diverse and contradictory. Existing systematic investigations are not adequate and further well-designed prospective studies are needed to clarify the effect of coffee on GERD.

Keywords: coffee, gastroesophageal reflux disease

\section{Introduction}

Gastroesophageal reflux disease (GERD) is a common disorder and the worldwide prevalence of the disease is steadily increasing. This condition is characterized by symptoms and/or complications caused by contents of the stomach leaking into the esophageal region (Vakil et al., 2006). Most GERD patients present with esophageal syndromes such as heartburn, regurgitation, chest pain, dysphagia, odynophagia, etc. Retrosternal burning and regurgitation are the hallmark GERD symptoms (Sawaya et al., 2012). Recent evidence has suggested that extraesophageal syndromes such as cough, reflux laryngitis, and asthma may also arise in the presence of GERD and recently the Montreal classification of GERD has divided the disease into esophageal and extraesophageal syndromes (Vakil et al., 2006). The growing obesity, diet and lifestyle, increased realization of extraesophageal symptom may be part of the potential explanations for the increasing prevalence of GERD (El-Serag, 2007; Djärv et al., 2012; Wu et al., 2007).

GERD is a chronic disease and patients are subject to frequent relapses, which negatively affect health-related quality of life (Armstrong et al., 2005). In Western countries, the prevalence of GERD is $10 \%$ to $20 \%$ of the population (Fedorak et al., 2010). The main cause of GERD is clear but the

*To whom correspondence should be addressed.

E-mail: zju_csh@126.com involvement of lifestyle for the development of GERD and the effect of lifestyle modification is not clear. GERD treatment is patient specific, but the overall goal is to reduce the symptoms and reverse any damage that may have occurred to the mucosal layer of the esophagus. Although lifestyle modifications may benefit some patients, these changes alone are unlikely to control all symptoms for the majority of patients (DeVault and Castell, 2005).

Coffee use is often discouraged in patients with GERD although little evidence exists linking coffee consumption and GERD incidence. Coffee is one of the most widely consumed beverages in the world with well documented stimulating effects on the central nervous system (Gutiérrez-Grobe et al., 2012). Coffee has been linked to irritation of the gastric mucosa, disruption of the mucosal barrier and increased risk of peptic ulcers. Epidemiological data has suggested that coffee acts as a stomach and esophageal irritant and may be associated with gastroesophageal reflux, which may lead to ulcers and cancer in the afflicted areas (Terry et al., 2000). However, a definitive relationship between coffee consumption and GERD has not yet been elucidated and few systematic reviews on the topic have been published. Therefore, the purpose of this article is to clarify the relationship between coffee intake and GERD through a review of the existing literature. 


\section{Sources of Information}

'Gastroesophageal reflux disease', 'GERD' and 'coffee' were used as search terms in the PubMed database, which returned 53 articles. The abstracts of all these articles were reviewed and 15 were original epidemiological studies that evaluated the relationship between GERD and coffee (Pandeya et al., 2012; Bhatia et al., 2011; Lee et al., 2011; Friedenberg et al., 2010; Nasseri-Moghaddam, et al., 2008; Dore et al., 2008; El-Serag et al., 2007; Zheng et al., 2007; Somi et al., 2006; Moraes-Filho et al., 2005; Nilsson et al., 2004; Wang et al., 2004; Castelo Vega et al., 2003; Conio et al., 2002; Chang et al., 1997). These articles were reviewed to systematically examine existing literature pertaining to coffee consumption, GERD symptoms and mucosal damage. Specific questions pertaining to this area of research were evaluated below.

\section{Results and Discussion}

Epidemiological studies that examined the relationship between coffee and GERD Of the 15 epidemiological studies, only 5 studies concluded that GERD symptoms were associated with coffee intake (Table 1) (Bhatia et al., 2011; Lee et al., 2011; Somi et al., 2006; Wang et al., 2004; Castelo Vega et al., 2003). These included an Indian prospective,

Table 1. The effect of coffee on GERD.

\begin{tabular}{|c|c|c|c|c|c|c|c|}
\hline No & Authors & Nation & $\begin{array}{c}\text { Year } \\
\text { published }\end{array}$ & Journal & Cases & Methods & Results \\
\hline 1 & Pandeya et al. & Australia & 2011 & Dis. Esophagus & 1,580 & $\begin{array}{l}\text { Self-reported information from a } \\
\text { population registry }\end{array}$ & NA \\
\hline 2 & Bhatia et al. & India & 2011 & $\begin{array}{l}\text { Indian J. } \\
\text { Gastroenterol. }\end{array}$ & 3,224 & $\begin{array}{l}\text { Prospective, multi-center (12 centers) } \\
\text { study using a questionnaire }\end{array}$ & + \\
\hline 3 & Lee et al. & Korea & 2011 & $\begin{array}{c}\text { Korean J. } \\
\text { Gastroenterol. }\end{array}$ & 450 & Questionnaire & + \\
\hline 4 & Friedenberg et al. & USA & 2010 & Obes. Res. Clin. Pract. & 503 & $\begin{array}{l}\text { Cross-sectional survey delivered by } \\
\text { in-home interviews, convenience } \\
\text { sampling, and targeted mailing. }\end{array}$ & NA \\
\hline 5 & $\begin{array}{l}\text { Nasseri-Moghaddam } \\
\text { et al. }\end{array}$ & Iran & 2010 & $\begin{array}{l}\text { Aliment. Pharmacol. } \\
\text { Ther. }\end{array}$ & 2,057 & Questionnaire & NA \\
\hline 6 & Dore et al. & Italy & 2008 & Dig. Dis. Sci. & 500 & Endoscopy and questionnaire & NA \\
\hline 7 & El-Serag et al. & USA & 2007 & $\begin{array}{c}\text { Clin. Gastroenterol. } \\
\text { Hepatol. }\end{array}$ & 113 & Questionnaire & NA \\
\hline 8 & Zheng et al. & Sweden & 2007 & Gastroenterology & 4,083 & Questionnaire & $\begin{array}{c}\text { Gender } \\
\text { dependent }\end{array}$ \\
\hline 9 & Somi et al. & Iran & 2006 & Saudi Med. J. & 620 & Cross-sectional study & + \\
\hline 10 & Moraes-Filho et al. & Brazil & 2005 & Arq. Gastroenterol. & 13,959 & Population study & NA \\
\hline 11 & Nilsson et al. & Sweden & 2004 & Gut & 3,135 & Case control study & NA \\
\hline 12 & Wang & China & 2004 & $\begin{array}{l}\text { World J. } \\
\text { Gastroenterol. }\end{array}$ & 2,789 & Questionnaire & $\stackrel{+}{\text { OR } 1.23}$ \\
\hline 13 & Castelo Vega et al. & Perú & 2003 & $\begin{array}{l}\text { Rev. Gastroenterol. } \\
\text { Peru }\end{array}$ & 645 & Case control study & $\stackrel{+}{+}+39$ \\
\hline 14 & Conio et al. & Italy & 2002 & Int. J. Cancer & 600 & Multicenter case-control study & NA \\
\hline 15 & Chang et al. & China & 1997 & Am. J. Gastroenterol. & 2,044 & Endoscopy and questionnaire & NA \\
\hline
\end{tabular}


Table 2. Tea/coffee consumption (\%) in study subjects with or without GERD, from the study of Bhatia et al. (2011).

\begin{tabular}{ccccc}
\hline Tea/coffee & Non GERD $(\mathrm{n}=2978)$ & GERD $(\mathrm{n}=245)$ & OR $(95 \%$ CI $)$ & $\mathrm{p}$-value \\
\hline None & $870(29.2 \%)$ & $39(15.9 \%)$ & Reference & 0 \\
1 -3 cups/day & $1686(56.6 \%)$ & $151(61.6 \%)$ & $2.901(1.894-4.443)$ & 0 \\
$>3$ cups/day & $423(14.4 \%)$ & $55(22.4 \%)$ & $1.452(1.047-2.012)$ & 0.025 \\
\hline
\end{tabular}

multi-center study, by Bhatia et al. (2011) that found a positive relationship between tea/coffee and GERD (Table 2). Lee et al. (2011) enrolled 450 patients from gastroenterology clinics and found that coffee intake was significantly associated with erosive esophagitis using a univariate analysis. Another cross-sectional study (Somi et al., 2006) also found drinking coffee was associated with higher prevalence of GERD symptoms. Wang et al. (2004) and Castelo Vega et al. (2003) found consumption of coffee was independently associated with symptomatic gastroesophageal reflux $(\mathrm{OR}=1.23$; CI: $0.17-2.00 \&$ OR $=4.39$; CI: $1.72-11.65)$.

Although 5 studies found a relationship between coffee consumption and GERD, the majority of studies found no significant relationship (Pandeya et al., 2012; Friedenberg et al., 2010; Nasseri-Moghaddam et al., 2008; Dore et al., 2008; El-Serag et al., 2007; Zheng et al., 2007; MoraesFilho et al., 2005; Nilsson, et al., 2004; Conio et al., 2002; Chang et al., 1997). A study that was derived from a population registry in Australia (Pandeya et al., 2012) found no evidence that frequent GERD symptoms were associated with coffee consumption. Similarly, a cross-sectional survey acquired via in-home interviews, convenience sampling, and targeted mailing, found no association between reflux disease and lifestyle choices such as coffee drinking (Friedenberg et al., 2010). Two studies from Italy revealed no correlation between coffee drinking and GERD (Nasseri-Moghaddam et al., 2008; Conio et al., 2002). El-Serag et al. (2007) conducted a nested case-control study to examine the prevalence and risk factors for current GERD symptoms in young adults with a history of childhood GERD. These authors found no relationship between coffee and GERD. A Brazilian national study that enrolled 13,959 adults was conducted by MoraesFilho et al. (2005). These authors evaluated the prevalence of heartburn and GERD from individuals in 22 Brazilian cities. Only $9.2 \%$ of heartburn patients and $9.5 \%$ of GERD patients reported drinking coffee. Chang et al. (1997) also observed that coffee or tea drinking did not contribute to the development of esophagitis.

Nilsson et al. (2004) collected and analysed data on the use of coffee and GERD using a case control design from two public health surveys. In the multivariate analysis there was a negative association between coffee intake and reflux symptoms. Additionally, there was an approximately $40 \%$ decrease in the risk of reflux symptoms among people who drank more than seven cups of coffee per day compared with those who drank less than one cup (OR: 0.6; 95\% CI: 0.4 $-0.7)$. However, the univariate analysis revealed a slight increase in the risk of reflux when the same groups above were compared (OR: 1.2; 95\% CI: $1.1-1.4$ ), although this increased risk was entirely explained by the confounding variable of tobacco smoking.

Interestingly, data from the Swedish Twin Registry (Zheng et al., 2007) revealed a gender-dependent association between coffee intake and GERD symptoms. In women coffee use was dose-dependently associated with risk of frequent GERD symptoms, with about a $45 \%$ increased risk among heavy users who drank more than 7 cups per day compared with non-users in the univariate analysis. However this association was not significant when BMI, smoking, and physical activity were accounted for in the multivariate analysis. The opposite trend was found in men. For men, there was a significant and inverse dose-dependent association between coffee consumption and GERD symptoms with a $25 \%$ decreased risk for heavy users. The gender difference in the associations was statistically significant (Zheng et al., 2007).

\section{Effect of coffee on GERD}

1. Is Caffeine related to GERD? Caffeine is a colorless, bitter-tasting substance that naturally occurs in foods such as coffee, cola, cocoa and tea. Several studies have examined the effects of caffeine on GERD. Wendl et al. (1994) found that regular coffee increases gastroesophageal reflux when compared to decaffeinated coffee. In a double-blind study by Pehl et al. (1997), 17 reflux patients performed two esophageal $\mathrm{pH}$ measurements $3 \mathrm{~h}$ after ingestion of 300 $\mathrm{mL}$ of either regular or decaffeinated coffee together with a standardized breakfast. The fraction time esophageal $\mathrm{pH}<4$ was calculated to a median of $17.9 \%$ for regular coffee. This was reduced to $3.1 \%$ after ingestion of decaffeinated coffee, suggesting that decaffeinated coffee reduces the esophageal acidity potentially via a reduction in esophageal reflux.

2. Different coffee and GERD Different types of coffee beans have different caffeine levels and subsequently, different coffee brands have different amounts of caffeine. In Brazer et al.'s double-blind and crossover study, 3 caffeinated coffees were used to investigated the effect on GERD: coffee 
A is a widely distributed roast and ground coffee available in the United States market; coffee B is a premium quality roast and ground coffee available in the European market, characterized by a "special" treatment; coffee C is the same coffee without the treatmen. And as a result, different coffees induce variations in gastroesophageal reflux in coffee-sensitive subjects (Brazer et al., 1995). Paradoxically, DiBaise (2003) compared the effect of different coffee-roasting processes on upper gastrointestinal symptoms in coffee-sensitive individuals and found that different coffee bean roasting process did not result in marked differences in coffee-induced symptoms. What makes the different results in different studies? First, their caffeine concentration may vary in different coffee beans and different types of coffee processing, which may also produce or release substances within coffee that buffer noxious elements either in the coffee itself or as a result of coffee-induced gastric secretion. Second, the relationship between symptoms and reflux episodes may depend on the presence of esophagitis or acid sensitivity. Third, it is likely that symptom frequency and severity are dependent not only on the degree of gastroesophageal reflux induced by coffee, but also the gastrointestinal tract. Last, individual variability accounts for the different responses to coffee drinking and there may be other factors which act in concert with coffee related GERD symptoms.

3. Gastric acid secretion GERD is the result of excessive gastroesophageal reflux of gastric juice and impaired esophageal clearance of the refluxate. GERD severity depends on lower esophageal sphincter dysfunction as well as the type and amount of fluid brought up from the stomach. The role of acid, weak acid and bile in the mechanism of esophageal mucosal damage and reflux symptoms is complex. Acid, which is the primary cause of heartburn and regurgitation, may be the principal factor in determining the severity of esophagitis (Richter, 2009).

Excessive production of gastric acid is the most common cause of acid reflux. Acid reflux is often characterized by heartburn, which is described as a burning sensation that starts at the stomach and goes up to the throat. Cohen and Booth (1975) compared the dose-response relations of regular coffee, decaffeinated coffee and caffeine for gastric acid secretion in normal subjects on a cup-equivalent basis. Regular coffee gave a maximal acid response of $20.9 \pm 3.6 \mathrm{mEq} / \mathrm{h}$, which was similar to that of decaffeinated coffee, $16.5 \pm 2.6$ $\mathrm{mEq} / \mathrm{h}$. Both values were higher than that of caffeine at 8.4 $\pm 1.3 \mathrm{mEq} / \mathrm{h}$, on a cup-equivalent basis. Therefore, the effects of caffeine may be moderated when ingested via coffee drinks.

Shoenut et al. (1998) conducted a prospective investigation into the impact of ingested liquids including coffee/tea, water, fruit juice, cola and beer on 24-h $\mathrm{pH}$ test scores. Total test time, total drink time, total minutes of $\mathrm{pH}<4.0$ during drinking, minutes of $\mathrm{pH}<4.0$ ten minutes before drink, and minutes of $\mathrm{pH}<4.0$ ten minutes following drink were compared between the beverages. The percentage of total time $\mathrm{pH}<4.0$ was not significantly different between any of the liquids, suggesting that the type of beverage had a minimal impact on esophageal $\mathrm{pH}$.

Boekema et al. (1999) concluded that coffee had no important effect on gastro-esophageal acid reflux in GERD patients using data from a randomized, controlled, crossover study. In this study, participants included seven GERD patients and eight healthy subjects. Each individual underwent $24 \mathrm{~h}$ esophageal $\mathrm{pH}$ and manometric monitoring after a day of coffee abstinence. At well-defined times, they ingested either $280 \mathrm{~mL}$ of regular coffee or $280 \mathrm{~mL}$ of water. Coffee or water was consumed $1 \mathrm{~h}$ after breakfast, during lunch, $1 \mathrm{~h}$ after dinner and after an overnight fast. Reflux and esophageal motility were assessed for the first hour after each coffee or water intake. The results showed that coffee had no effect on postprandial acid reflux time or number of reflux episodes, in both GERD and healthy subjects. Coffee increased the percentage acid reflux time only when ingested in the fasting period in GERD patients, but not in the healthy subjects. There was no effect of coffee consumption on postprandial lower esophageal sphincter pressure (LESP), patterns of LESP associated with reflux episodes or esophageal contractions.

4. Lower-esophageal-sphincter (LES) pressure The LES is a tight ring of muscle located at the junction of the esophagus and stomach that is usually closed to prevent the stomach contents from moving into esophagus. LES together with the crural diaphragm are the major antireflux barriers protecting the esophagus from reflux of gastric content (Hershcovici et al., 2011).

Gudjonsson et al. (1995) studied the effects of coffee and tea on LES function in a blinded crossover study of 12 healthy subjects. The results showed that LESP was significantly lower after intake of regular coffee and tea, but not after decaffeinated coffee and water. These findings suggest that decaffeinated coffee does not have adverse effects on LES function. In another study, heartburn subjects had diminished basal LES pressure, $8.3 \pm 1.1 \mathrm{mmHg}$, compared to asymptomatic subjects, $19.4 \pm 1.3 \mathrm{mmHg}$ after drinking four separate doses of coffee $(\mathrm{P}<0.01)$ (Cohen, 1980). However, Cohen et al. found contradictory results in that LES pressure was significantly increased by both regular and decaffeinated coffee, although caffeine did not significantly affect LES pressure (Cohen and Booth, 1975). 


\section{Summary}

The prevalence of GERD patients was increasing in the world and the presence of GERD may affect the patients' quality of life. Treatment aims at decreasing the amount of reflux or reducing damage to the lining of the esophagus from refluxed materials. Avoiding foods and beverages that can weaken the LES is recommended. These foods may include chocolate, peppermint, fatty foods, coffee, and alcoholic beverages. Coffee consumption in China is growing fast in recent years and a lot of people enjoy it. However, many patients complained that their stomach starts to be painful, burning immediately after coffee drinking. Coffee might in some way induce or exacerbate GERD symptoms from majority of the patients. However, the relationship between GERD and coffee consumption is not clear given the existing literature. Some of the diverse and contradictory results can be partly attributed to the different definition of GERD, different study design, different kind of coffee and individual variability of responses to coffee drinking. Further well-designed and large population based prospective studies are needed to clarify the effect of coffee on GERD.

Acknowledgements The authors thank the grant support from the Traditional Chinese Medicine Program of Zhejiang Province (No. 2010ZA053).

\section{References}

Armstrong, D., Marshall, J.K., Chiba, N., Enns, R., Fallone, C.A., Fass, R., Hollingworth, R., Hunt, R.H., Kahrilas, P.J., Mayrand, S., Moayyedi, P., Paterson, W.G., Sadowski, D. and van Zanten, S.J. (2005). Canadian Association of Gastroenterology GERD Consensus Group. Canadian Consensus Conference on the management of gastroesophageal reflux disease in adults - update 2004. Can. J. Gastroenterol., 19, 15-35.

Bhatia, S.J., Reddy, D.N., Ghoshal, U.C., Jayanthi, V., Abraham, P., Choudhuri, G., Broor, S.L., Ahuja, V., Augustine, P., Balakrishnan, V., Bhasin, D.K., Bhat, N., Chacko, A., Dadhich, S., Dhali, G.K., Dhawan, P.S., Dwivedi, M., Goenka, M.K., Koshy, A., Kumar, A., Misra, S.P., Mukewar, S., Raju, E.P., Shenoy, K.T., Singh, S.P., Sood, A. and Srinivasan, R. (2011). Epidemiology and symptom profile of gastroesophageal reflux in the Indian population: report of the Indian Society of Gastroenterology Task Force. Indian J. Gastroenterol., 30, 118-127.

Boekema, P.J., Samsom, M. and Smout, A.J. (1999). Effect of coffee on gastro-oesophageal reflux in patients with reflux disease and healthy controls. Eur. J. Gastroenterol. Hepatol., 11, 12711276.

Brazer, S.R., Onken, J.E., Dalton, C.B., Smith, J.W. and Schiffman, S.S. (1995). Effect of different coffees on esophageal acid contact time and symptoms in coffee-sensitive subjects. Physiol. Behav.,
57, 563-567.

Castelo Vega, J.M., Olivera Hermoza, R., Páucar Sotomayor, H. and Flores Aldea, J.C. (2003). Gastroesophageal reflux: clinical, endoscopic characteristics and associated risk factors. Rev. Gastroenterol. Peru, 23, 41-48 (in Spanish).

Chang, C.S., Poon, S.K., Lien, H.C. and Chen, G.H. (1997). The incidence of reflux esophagitis among the Chinese. Am. J. Gastroenterol., 92, 668-671.

Cohen, S. (1980). Pathogenesis of coffee-induced gastrointestinal symptoms. N. Engl. J. Med., 303, 122-124.

Cohen, S. and Booth, G.H. Jr. (1975). Gastric acid secretion and lower-esophageal-sphincter pressure in response to coffee and caffeine. N. Engl. J. Med., 293, 897-899.

Conio, M., Filiberti, R., Blanchi, S., Ferraris, R., Marchi, S., Ravelli, P., Lapertosa, G., Iaquinto, G., Sablich, R., Gusmaroli, R., Aste, H. and Giacosa, A. (2002). Gruppo Operativo per lo Studio delle Precancerosi Esofagee (GOSPE). Risk factors for Barrett's esophagus: a case-control study. Int. J. Cancer, 97, 225-229.

DeVault, K.R. and Castell, D.O. (2005). American College of Gastroenterology. Updated guidelines for the diagnosis and treatment of gastroesophageal reflux disease. Am. J. Gastroenterol., 100, 190-200.

DiBaise, J.K. (2003). A randomized, double-blind comparison of two different coffee-roasting processes on development of heartburn and dyspepsia in coffee-sensitive individuals. Dig. Dis. Sci., 48, 652-656.

Djärv, T., Wikman, A., Nordenstedt, H., Johar, A., Lagergren, J. and Lagergren, P. (2012). Physical activity, obesity and gastroesophageal reflux disease in the general population. World J. Gastroenterol., 18, 3710-3714.

Dore, MP., Maragkoudakis, E., Fraley, K., Pedroni, A., Tadeu, V., Realdi, G., Graham, D.Y, Delitala, G. and Malaty, H.M. (2008). Diet, lifestyle and gender in gastro-esophageal reflux disease. Dig. Dis. Sci., 53, 2027-2032.

El-Serag, H.B. (2007). Time trends of gastroesophageal reflux disease: a systematic review. Clin. Gastroenterol. Hepatol., 5, 17-26. El-Serag, H.B., Richardson, P., Pilgrim, P. and Gilger, M.A. (2007). Determinants of gastroesophageal reflux disease in adults with a history of childhood gastroesophageal reflux disease. Clin. Gastroenterol. Hepatol., 5, 696-701.

Fedorak, R.N., Veldhuyzen van Zanten, S. and Bridges, R. (2010). Canadian Digestive Health Foundation Public Impact Series: Gastroesophageal reflux disease in Canada: Incidence, prevalence, and direct and indirect economic impact. Can. J. Gastroenterol., 24, 431-434.

Friedenberg, F.K., Rai, J., Vanar, V., Bongiorno, C., Nelson, D.B., Parepally, M., Poonia, A., Sharma, A., Gohel, S. and Richter, J.E. (2010). Prevalence and risk factors for gastroesophageal reflux disease in an impoverished minority population. Obes. Res. Clin. Pract., 4, e261-e269. 
Gudjonsson, H., McAuliffe, T.L. and Kaye, M.D. (1995). The effect of coffee and tea upon lower esophageal sphincteric function. Laeknabladid, 81, 484-488 (in Icelandic).

Gutiérrez-Grobe, Y., Chávez-Tapia, N., Sánchez-Valle, V., Gavilanes-Espinar, J.G., Ponciano-Rodríguez, G., Uribe, M. and Méndez-Sánchez, N. (2012). High coffee intake is associated with lower grade nonalcoholic fatty liver disease: the role of peripheral antioxidant activity. Ann. Hepatol., 11, 350-355.

Hershcovici, T., Mashimo, H. and Fass, R. (2011). The lower esophageal sphincter. Neurogastroenterol. Motil., 23, 819-830.

http://www.noo.org.uk/NOO_about_obesity/international/ (May 15, 2012)

Lee, S.J., Jung, M.K., Kim, S.K., Jang, B.I., Lee, S.H., Kim, K.O., Kim, E.S., Cho, K.B., Park, K.S., Kim, E.Y., Jung, J.T., Kwon, J.G., Lee, J.H., Yang, C.H., Park, C.K., Seo, H.E. and Jeon, S.W. (2011). Clinical characteristics of gastroesophageal reflux disease with esophageal injury in korean: focusing on risk factors. Korean J. Gastroenterol., 57, 281-287.

Moraes-Filho, J.P., Chinzon, D., Eisig, J.N., Hashimoto, C.L. and Zaterka, S. (2005). Prevalence of heartburn and gastroesophageal reflux disease in the urban Brazilian population. Arq. Gastroenterol., 42, 122-127.

Nasseri-Moghaddam, S., Mofid, A., Ghotbi, M.H., Razjouyan, H., Nouraie, M., Ramard, A.R., Zaer-Rezaie, H., Habibi, R., RafatZand, K. and Malekzadeh, R. (2008). Epidemiological study of gastro-oesophageal reflux disease: reflux in spouse as a risk factor. Aliment. Pharmacol. Ther, 28, 144-153.

Nilsson, M., Johnsen, R., Ye, W., Hveem, K. and Lagergren, J. (2004). Lifestyle related risk factors in the aetiology of gastrooesophageal reflux. Gut, 53, 1730-1735.

Pandeya, N., Green, A.C. and Whiteman, D.C.; Australian Cancer Study (2012). Prevalence and determinants of frequent gastroesophageal reflux symptoms in the Australian community. Dis. Esophagus, 25, 573-583.

Pehl, C., Pfeiffer, A., Wendl, B. and Kaess, H. (1997). The effect of decaffeination of coffee on gastro-oesophageal reflux in patients with reflux disease. Aliment. Pharmacol. Ther, 11, 483-486.

Richter, J.E. (2009). Role of the gastric refluxate in gastroesophageal reflux disease: acid, weak acid and bile. Am. J. Med. Sci., 338, 89-95.

Sawaya, R.A., Macgill, A., Parkman, H.P. and Friedenberg, F.K. (2012). Use of the Montreal global definition as an assessment of quality of life in reflux disease. Dis. Esophagus, 25, 477-483.

Shoenut, J.P., Duerksen, D. and Yaffe, C.S. (1998). Impact of ingested liquids on 24-hour ambulatory pH tests. Dig. Dis. Sci., 43, 834-839.

Somi, M.H., Farhang, S., Mirinezhad, K., Jazayeri, E., NasseriMoghaddam, S., Moayeri, S. and Yasrebinia, S. (2006). Prevalence and precipitating factors of gastroesophageal reflux disease in a young population of Tabriz, Northwest of Iran. Saudi Med. J., 27, 1878-1881.

Terry, P., Lagergren, J., Wolk, A. and Nyren, O. (2000). Reflux-inducing dietary factors and risk of adenocarcinoma of the esophagus and gastric cardia. Nutr. Cancer, 38, 186-191.

Vakil, N., van Zanten, SV., Kahrilas, P., Dent, J. and Jones, R.; Global Consensus Group (2006). The Montreal definition and classification of gastroesophageal reflux disease: a global evidence-based consensus. Am. J. Gastroenterol., 101, 1900-1920.

Wang, J.H., Luo, J.Y., Dong, L., Gong, J. and Tong, M. (2004). Epidemiology of gastroesophageal reflux disease: a general population-based study in Xi'an of Northwest China. World J. Gastroenterol., 10, 1647-1651.

Wendl, B., Pfeiffer, A., Pehl, C., Schmidt, T. and Kaess, H. (1994). Effect of decaffeination of coffee or tea on gastro-oesophageal reflux. Aliment. Pharmacol. Ther, 8, 283-287.

Wu, J.C., Mui, L.M., Cheung, C.M., Chan, Y. and Sung, J.J. (2007). Obesity is associated with increased transient lower esophageal sphincter relaxation. Gastroenterology, 132, 883-889.

Zheng, Z., Nordenstedt, H., Pedersen, N.L., Lagergren, J. and Ye, W. (2007). Lifestyle factors and risk for symptomatic gastroesophageal reflux in monozygotic twins. Gastroenterology, 132, 87-95. 